\title{
Characterization of The Heat Transfer on Spray Quenching for Different Material Properties
}

\author{
Sabariman $^{1}$, E. Specht ${ }^{2}$ \\ ${ }^{I}$ Dept. of Electrical Engineering, Industrial Technology Faculty, Universitas Internasional Batam, \\ Jl. Gajahmada, Sei-Ladi Baloi, Batam 29442, Indonesia \\ ${ }^{2}$ Institute of Fluid Dynamics and Thermodynamics, Faculty of Process and System Engineering, University of Magdeburg, \\ Universitätplatz 2, 39106 Magdeburg, Germany
}

\section{ARTICLE INFO}

Article history:

Received 16 April 2019

Received in revised form 25 February 2021 Accepted 8 March 2021

Keywords:

Spray quenching

Boiling regime

Leidenfrost temperature

DNB temperature

Maximum heat flux

\begin{abstract}
A B S T R A C T
A broad range of water spray applications as a means of two-phase cooling scheme has encouraged researches in the thermal management system to support safety and process efficiency in industries. In the application of above saturation temperature, the cooling process follows the boiling curve where the dissipated heat flux is figured out as a function of the wall temperature. Knowledge on constructing the boiling curve is an essential part in order to define the moving boundary, and boundary value problems occur in metal cooling process analysis involving heat transfer and phase change. The objective of the research was to characterize the boiling parameters on different materials in the regime of film boiling, transition boiling, and nucleate boiling as the basis for its boiling curve construction. To explain the influence of material properties, this work is featuring, firstly, the calculated vapor film thickness in film boiling regime by promoting self-developed analytical model of single droplet and, secondly, the calculated boiling width which indicates a strong combination of surface temperature and heat flux observed as the boiling phenomena. This is obtained by calculating the propagation of wetting front and $100{ }^{\circ} \mathrm{C}$ points. This experimental work employed a volumetric spray flux of $4.2,10$ and $13.7 \mathrm{~kg} / \mathrm{m}^{2} \mathrm{~s}$ to cool a hot metal samples of aluminum alloy AA6082 and nickel heated up to $560{ }^{\circ} \mathrm{C}$. An infrared camera was used to record the temperature drop over time. Heat flux calculation follows the numerical procedure according to $1 \mathrm{D}$ energy balance model. Calculated vapor film thickness explains why the HTC tends to increase with the decrease of the surface temperature. Leidenfrost and Departure from Nucleate Boiling (DNB) temperatures are found to be inversely proportional to the heat penetration coefficient of the metal while maximum heat flux and boiling width increase with it.
\end{abstract}

(C) 2021 Atom Indonesia. All rights reserved

\section{INTRODUCTION}

Quenching refers to the process of rapid cooling with the use of low temperature fluid applied to a high temperature surface according to a certain technique. There are some methods of quenching with regard to their respective applications. Metal processing industry is an example. Jet impingement, spray cooling and cooling with array of jets in the form of mold are the methods commonly used in the applications. Jet Impingement technique is widely applied when a very intensive cooling is a must in order to comply

\footnotetext{
*Corresponding author.

E-mail address: sabariman@uib.ac.id

DOI: https://doi.org/10.17146/aij.2021.947
}

with a product quality requirement, e.g., in the hardening process. When uniform cooling is prioritized, spray cooling technique is normally chosen, e.g., in the continuous casting process. Cooling with array of jets from mould is applied especially in the direct chill (DC) casting facility from which high conductivity metals are produced. Array of water jets will produce water curtain in order to extract heat efficiently in the secondary cooling zone.

Similar to the water-cooled nuclear reactors, it is necessary to have an emergency core cooling (ECC) system as a part of preventive actions, especially in the occurance of a loss of coolant accident (LOCA) [1,2]. Under this situation, shutting down the reactor will not prevent the fuel 
el153ement from severe overheating. Providing water spray as an ECC will expedite heat removal from the fuel element. Spray cooling is incorporated into refrigeration systems especially in lowtemperature applications [3]. When a spray of emergency cooling water immediately in contact with a hot fuel element, a vapor blanket will be formed in the interface between solid-liquid contacts. This vapor layer from heat transfer point of view has significantly reduced the heat transfer rate due to poor conduction through the vapor layer. In this stage, regime of film boiling is formed. As the process is continued, then the surface cools down until suddenly the vapor blanket collapsed. This point of condition is well-known as the Leidenfrost transition marked by partially-direct contact of the liquid to the hot surface. This situation defines the regime of transition boiling. After that the heat flux continuously increases as more liquid in contact to the hot surface. It keeps increasing until it reaches a maximum value with the value far above the one in the film boiling. The temperature at this critical point is so-called as temperature of departure from nucleate boiling (DNB). Subsequently, boiling continues to the regime of nucleate boiling followed by a significant decrease of heat flux. Meanwhile, the surface temperature keeps dropping until it reaches $100{ }^{\circ} \mathrm{C}$ (for water) and, at this point downward, single-phase forced convection is started until it reaches the ambient temperature.

In analyzing the consequences of a LOCA, it is of great importance to understand the length of film boiling regime taking place. It is considered from spray initiation to the start of wetting front movement, defined as Leidenfrost transition. As the existance of film boiling regime determines the total duration of quenching process of the fuel bundle, further delay might bring cladding to the overheating state or even a failure of the emergency cooling system, the worst case [1,2]. Fu et al. [4] reported their study of using brass rod to simulate the quenching process of the nuclear fuel rod after the power plant shutdown. Information on Leidenfrost temperature and maximum heat flux were highlighted. Reported by Liang and Mudawar [5], other than that, spray cooling was also commonly used for some applicatons aimed to control heat flux, e.g., heat exchanger for hydrogen storage, fusion reactor blanket, particle accelerator targets, and magnetohydrodynamic (MHD) electrode walls just to name a few. The application focus was maintaining the critical heat flux limit so that it was conditioned safely in the nucleate boiling regime. Then technically spray chamber was configurated appropriately to facilitate this cooling process.
Results from works done by many researchers have been reported on the characteristics parameters of the boiling heat transfer, e.g., HTC in film boiling, the Leidenfrost temperature to start transition boiling, and DNB temperature with its maximum heat flux to indicate the beginning of nucleate boiling. They found HTC increases with the spray flux [3, 5-10] and inversely proportional to the surface temperature [7,11]. Others reported the work on the attempt to reduce the thickness of vapor layer by applying additive of $\mathrm{Na}_{2} \mathrm{CO}_{3}$ in high spray flux value [12]. Leidenfrost temperature is influenced by some parameters, e.g., water spray flux [8, 13-15], initial temperature $[1,11]$, material properties $[1,13,16]$, water temperature [16-19], and salt content in the cooling water $[2,11,20,21]$. Liang and Mudawar [22] highlighted their finding as no reliable correlations or models that could predict Leidenfrost temperature accurately. Therefore, it calls for a lot of experiments to verify all possible sources of influence including wall material with large difference of thermophysical properties. Reviews on the factors influencing maximum heat flux were reported for the different spray flux $[3,8,23,24]$, salinity or additives [20,21,24] and different pressure $[14,23,25,26]$. Varying the corresponding DNB temperature due to spray flux $[8,21,23]$ and salinity or additives $[20,21,24]$ was also reported.

This study were carried out to characterize the boiling behaviour on different materials under spray quenching. This knowledge then were capitalized to construct boiling curve for moving boundary and boundary value problems that occur in cooling process analysis involving heat transfer and phase change. In its process, it offers two novelties: 1) The influence of material properties on key parameters, i.e., calculated vapor film thickness in film boiling based on analytical model of singledroplet; it is missing in many discussions, therefore the impact is verified through a lot of experiments; 2) The boiling width under different material over distance according to the calculated propagation of wetting front and $100{ }^{\circ} \mathrm{C}$ points. By obtaining this information, knowledge on the boiling curve can be constructed. It can be used for moving boundary condition along the cooling process. In this work, with the use of infrared thermography measurement, it is much easier to handle and provide more comprehensive temperature historical data with high accuracy over the distance. It helps to diminish the difficulties encountered in many previous works when thermo-element was used for the temperature measuring device, where the space resolution was always a major issue therein. 


\section{SINGLE DROPLET MODEL IN THE REGIME OF FILM BOILING}

From the positive axis on the right side, a film boiling regime is illustrated as a dry zone. A single droplet model representing the spray cooling mechanism to the hot surface has been explained comprehensively by Sabariman et al. [11].

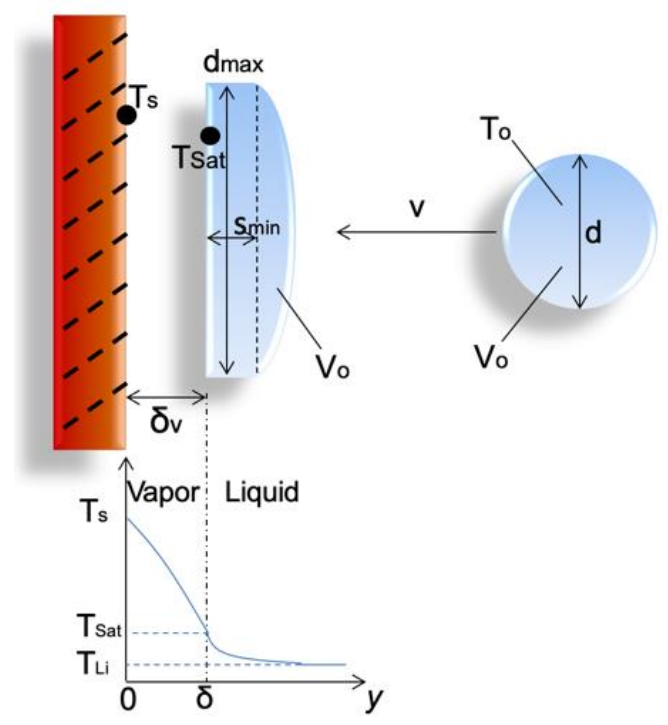

Fig. 1. Schematic diagram of a bounced droplet landing on the hot surface [11].

They used the assumption that once a single droplet lands upon the hot surface, the temperature of the droplet surface on the metal side would be equal to boiling temperature. In that sense, the temperature gradient in the fluid would be decisive to the heat transfer. Figure 1 shows the schematic diagram of a bounced droplet landing on the hot surface with the maximum expansion. As it is within a relatively short contact time, then the heat conduction principle as a semi-infinite body in the droplet can be applied. Therefore, the temperature distribution within the droplet will follow Eq. (1) [27]:

$$
\frac{T-T_{S a t}}{T_{S a t}-T_{L i}}=\operatorname{erf}(\eta)=\operatorname{erf}\left(\frac{x}{2 \sqrt{\alpha \cdot t_{c o n}}}\right)
$$

where $\alpha=\frac{\lambda}{\rho . C}$ is defined as water thermal diffusivity, $x$ is the distance, $T_{\text {sat }}$ and $T_{L i}$ refer to the water boiling temperature and the droplet initial temperature, respectively. And the applied contact time according to Labeish [28] is in Eq. (2).

$$
t_{\text {con }}=2 \cdot \frac{d}{v}
$$

where $d$ and $v$ are the droplet diameter and velocity, respectively. According to the calculated result, there is no significant change in temperature of the opposite side [11]. Therefore, the heat flux into the droplet can be defined as Eq. (3).

$$
\dot{q}_{d}=\sqrt{\frac{(\lambda \cdot \rho \cdot c)_{L i}}{\pi \cdot t_{c o n}}}\left(T_{S a t}-T_{L i}\right)
$$

where $\lambda, \rho, c$ are conductivity, density, and specific heat capacity of the liquid, respectively. This heat flux corresponds to that discharged by the wall. By assuming that the heat flux is constant over short contact time or equals to $\bar{q}_{d}$, one can obtain a good approximation of the wall temperature profile in Eq. (4).

$$
T_{s}=T_{\text {init }}-\left[\overline{\dot{q}}_{d} \sqrt{\frac{\pi \cdot t_{c o n}}{(\lambda \cdot \rho \cdot c)_{w}}}\right]
$$

where $T_{\text {init }}$ is the initial temperature of the sample and $\lambda, \rho, c$ are conductivity, density, and specific heat capacity of the sample, respectively. Then, the vapor film thickness on the basis of single droplet can be estimated in Eq. (5).

$$
\delta_{v}=\frac{\lambda_{v}}{\dot{q}}\left(T_{s}-T_{s a t}\right)
$$

where $\lambda_{v}$ is vapour conductivity and $\dot{q}$ is the heat flux from the surface of the sample proportional to the droplets number.

\section{EXPERIMENTAL METHODS}

\section{Experimental setup}

This experimental work was conducted with the use of facility arranged as shown in Fig. 2. All samples were heated up inside the electrical furnace with black painting in camera side for the sake of better emissivity. Specifically, for the purpose of material properties comparison, disc samples of Nickel and Aluminum Alloy AA6082 were chosen in this experiment. Scientifically, Nickel and Aluminum Alloy AA6082 are the two non-ferrous metals representing two different casting process from which they are produced. Nickel is produced through continuous casting process while AA6082 is through direct chill casting. Besides, they have different thermophysical properties which are suspected for the reason of having different quenching characteristics. They were heated up to $560{ }^{\circ} \mathrm{C}$ as the optimum point for comparing AA6082 and Nickel. Nickel physically can undergo a higher 
temperature but not for AA6082. Under this designated temperature, both AA6082 and Nickel are still good physically and providing feasibility to see some phenomena of interest, e.g., film boiling and Leidenfrost transition, for analysis. Physical properties of both materials are listed in Table 1 and they are assumed to be temperature independent through the whole experimental works and calculations.

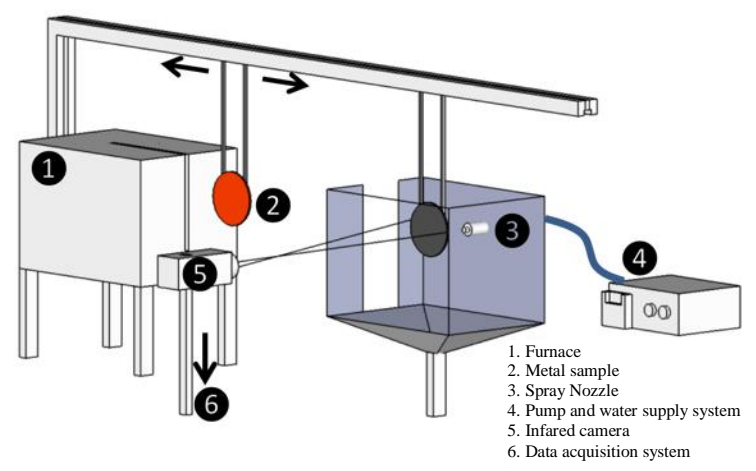

Fig. 2. Construction of spray quenching facility.

Table 1. Physical properties of materials.

\begin{tabular}{lcc}
\hline \multicolumn{1}{c}{ Parameter } & Nickel & AA6082 \\
\hline Disc diameter & $140 \mathrm{~mm}$ & $140 \mathrm{~mm}$ \\
Disc thickness & $2 \mathrm{~mm}$ & $3 \mathrm{~mm}$ \\
Material density & $8908 \mathrm{~kg} / \mathrm{m}^{3}$ & $2770 \mathrm{~kg} / \mathrm{m}^{3}$ \\
Thermal conductivity of & 91 & $170 \mathrm{~W} / \mathrm{m} / \mathrm{K}$ \\
material & & \\
Specific heat of material & 440 & $1050 \mathrm{~J} / \mathrm{kg} / \mathrm{K}$ \\
\hline
\end{tabular}

Once the designated temperature was reached, sample was quickly taken out and slided through the rail to a designated position where the center point of sample, the camera focus, and the center point of spray cone were in line. This transfer process was proven to cause not more than $2 \mathrm{~K}$ of temperature drop. Once the spray cover was released, the quenching process would start taking place while at the same time, data acquisition system was activated to record the temperature history during the process.

\section{Determination of emissivity}

An infrared camera was used to record the temperature drop over time during the quenching process. Therefore, it is very important to set a proper value of emissivity in measuring the temperature of black surface accurately. For this purpose, before conducting spray quenching experiment, a small experiment had been done to calibrate the emissivity of a graphite coating. Two identical size and kind of metal samples heated up to $560{ }^{\circ} \mathrm{C}$ were connected together with a thermo-element firmly fixed between them.
This thermoelement was connected to temperature data logger for data acquisition. Subsequently, the cooling process was kept under natural convection until it reached the designated temperature of $150{ }^{\circ} \mathrm{C}$. For every 30 second point of time, both temperature readings from infrared camera and data logger were compared simultaneously along the range. Readings from the thermo-element then were used to calibrate those readings with the IR camera by adjusting the emissivity value accordingly. This measurement procedure resulted in an average emissivity value for the black surface of $0.9 \pm 0.1$. To support the measurement accuracy, the thermal image was set within the range of $240 \times 80$ pixels with a high frame rate of $150 \mathrm{~Hz}$.

\section{Spray flux measurement}

To quantify a spray flux, an aligned formation of brass tubes with the plastic bottle in every bottom end is used to collect the water for a fixed period. Spray flux values are yielded from the equation of $\dot{m}=m_{\mathrm{d}} /(A . \Delta t)$, a fraction of the measured mass of the water droplets $m_{\mathrm{d}}$ to the product of the tubes diameter $\mathrm{A}$ and time $\Delta t$. From the repeated experiments, the results were fluctuating within the range of $\pm 4 \%$. It was then accepted to be the accuracy of the measurement.

\section{Repeatability Measurement}

The IR camera specifications drives the accuracy of temperature measurement which is of 1-2 K. During the experimental sequences, repetitions were carried out for 3 times. The presented results were only those which have acceptable repeatability within $5 \%$ fluctuation range. Identified factors potentially generate variability in measurement were blocked and randomized; therefore, poor repeatability was assumed to be out of systematic error [21].

\section{Energy balance analysis and accuracy}

Heat transfer during spray quenching of metal disc can be calculated with use of 1D energy balance model. By considering a control volume of the disc as discussed in other publication [21], it yields as in Eq. (6).

$$
\begin{aligned}
\alpha_{s p}\left(\mathrm{~T}_{s}-\mathrm{T}_{s p}\right) & =\dot{\mathrm{q}}_{s p} \\
& =\lambda \mathrm{s} \frac{1}{\mathrm{r}} \frac{\partial}{\partial \mathrm{r}}\left(\mathrm{r} \frac{\partial \mathrm{T}_{s}}{\partial \mathrm{r}}\right)-\rho \mathrm{s} \mathrm{c} \frac{d \mathrm{~T}_{s}}{d t}
\end{aligned}
$$


where $\alpha_{s p}, T_{s}, T_{s p}, \dot{q}_{s p}, \lambda, s, r, \rho$ and $c$ are specifically defined in the nomenclature, respectively.

\section{Comparison with 2D inverse analysis}

In $1 \mathrm{D}$ analysis, only radial conduction was considered for the calculation, and it was assumed that the temperature differences across the sample thickness were negligible. However, during the rapid transient, which is in the range of transition and nucleate boiling regions, this assumption in many discussions is suspected untenable as much higher temperature differences across the plate thickness are to be expected.

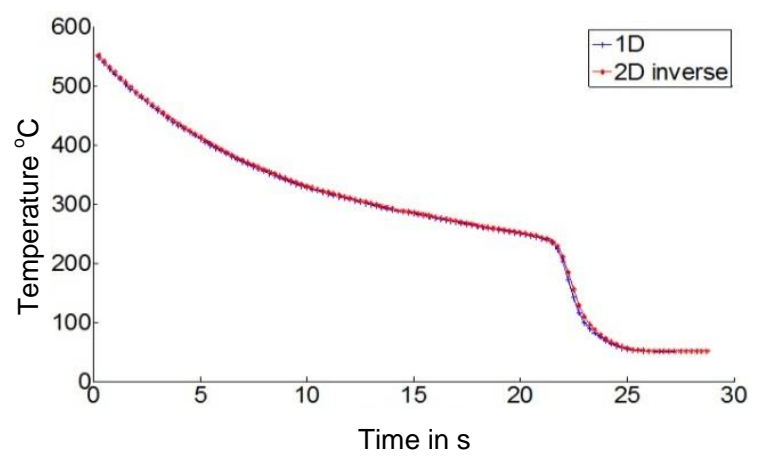

Fig. 3. Temperature profile of measured vs calculated (2D inverse analysis).

Therefore, a comparison between 1D analysis and $2 \mathrm{D}$ inverse analysis is represented by Figs. 3-6, related to this work. This analysis is based on the experimental data of spray quenching of nickel with impingement density of $10 \mathrm{~kg} / \mathrm{m}^{2} \mathrm{~s}$.

Figure 3 depicts the temperature profile of measured side and the calculated temperature with the use of 2D inverse analysis. The calculated time constant of the plate is in Eq. (7).

$$
\tau=\frac{\rho \cdot c_{\mathrm{p}} \cdot \mathrm{s}^{2}}{\lambda}
$$

On the basis of thermophysical data in Table 1, $\tau=0.174 \mathrm{~s}$ was obtained. This value is considered negligible compared to the time elapsing between the Leidenfrost and the DNB point which is about $1 \mathrm{~s}$.

Furthermore, Fig. 4 depicts temperature difference for the whole boiling regime between the measured side and the calculated temperature with the use of 2D inverse analysis. Immediately after the Leidenfrost point, higher temperature differences are were observed between front and back side of the sample. The highest temperature difference is at the DNB point which is of $15 \mathrm{~K}$. This fact proofs that there will be higher error for any parameter estimated with the use of 1D analysis in the regime of transition and nucleate boiling. However, for the practical purpose these temperature differences are considered still acceptable.

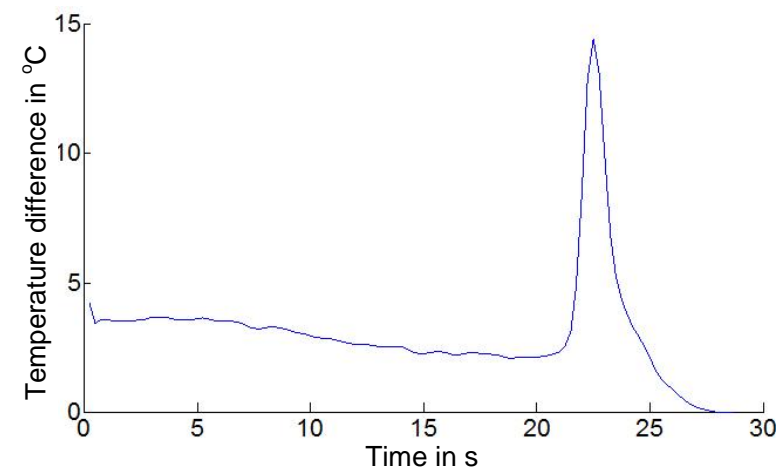

Fig. 4. Temperature differences of measured vs calculated (2D inverse analysis)

The calculated heat flux of 1D and 2D inverse analysis for the whole boiling regime is depicted in Fig. 5. Within film boiling regime, in average, the calculated heat flux of 1D analysis results in about $0.05 \mathrm{MW} / \mathrm{m}^{2}$ higher than 2D inverse analysis. There is no difference of the estimated Leidenfrost temperature between $1 \mathrm{D}$ and $2 \mathrm{D}$ analysis.

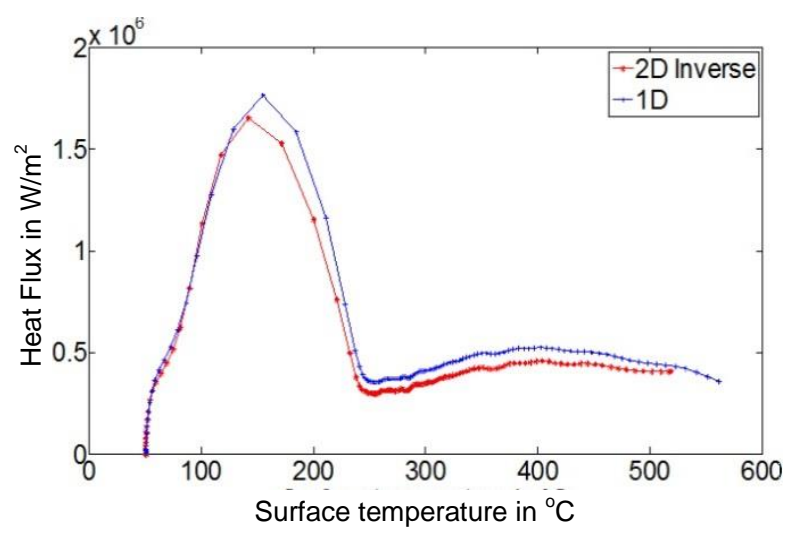

Fig. 5. Calculated heat flux differences of $1 D$ vs $2 D$ inverse analysis.

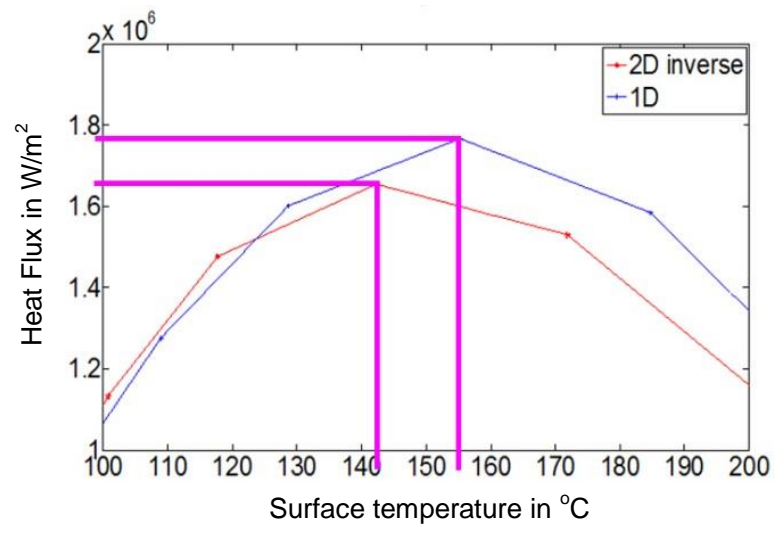

Fig. 6. Enlarged calculated heat flux differences (1D Vs 2D) inverse analysis for the transition and nucleate boiling region. 
Enlarged scale to specifically zoom in the temperature range of transition and nucleate boiling region is shown in Fig. 6. There is about $10-15 \mathrm{~K}$ difference in term of DNB temperature and about $0.15 \mathrm{MW} / \mathrm{m}^{2}$ in term of maximum heat flux.

\section{Determination of Leidenfrost and DNB temperature points}

In this research work, determination of Leidenfrost point was referring to the position where the minimum peak of the second derivative of temperature over time function. Meanwhile, the point of DNB temperature was obtained by aligning the maximum point of calculated heat flux to the measured temperature. Detailed review of the determination of these two parameters were presented in previous publication [21].

\section{RESULTS AND DISCUSSION}

\section{Regime of film boiling}

In the regime of film boiling, the vapor film created between the hot surface and the water droplet acts as insulation for the heat transfer. What is shown in Fig. 7 gives an inference that the heat transfer in the regime of film boiling is almost independent from material properties.

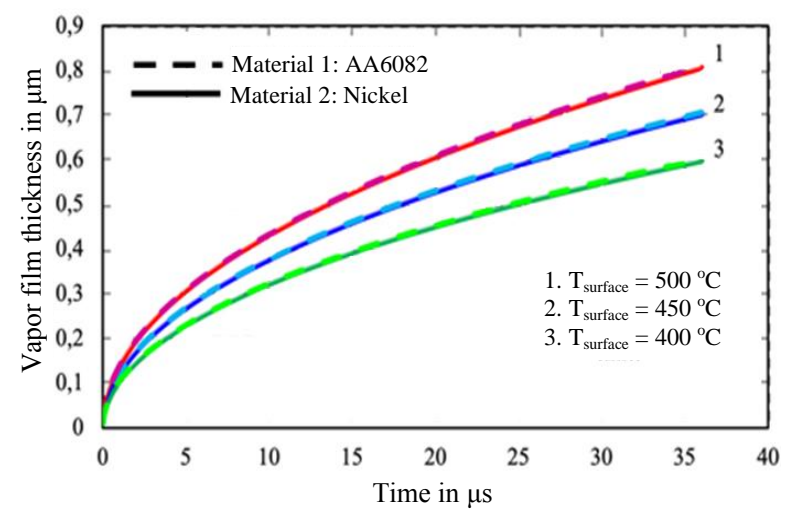

Fig. 7. Calculated vapor film thickness of a single droplet in the regime of film boiling.

However, it also gives another fact that the favor film thickness decreases with the surface temperature. This fact agrees with the results summarized in Fig. 8 showing the HTC as a function of the surface temperature. The HTC increases with the decrease of the surface temperature [29]. The reason for this is that the favor film thickness decreases with the surface temperature. A reduction of the vapor film thickness will lead to the increase of the heat transfer performance.
From Fig. 8 it is also obviously noticed that spray flux is the dominant factor influencing the heat transfer coefficient in the film boiling regime. Other than that, as mentioned in the previous paragraph, the surface temperature plays a major role as HTC increases with the surface temperature decrease. Furthermore, it can be observed that in the range of $400-500{ }^{\circ} \mathrm{C}$ by increasing the impingement density from $4 \mathrm{~kg} / \mathrm{m}^{2} \mathrm{~s}$ to $10 \mathrm{~kg} / \mathrm{m}^{2} \mathrm{~s}$ has increased HTC to a factor of 50 to $75 \%$. Reducing the surface temperature has increased HTC to a factor of 25 to $40 \%$. Changing material properties of the samples only results in the increase of HTC to a factor of 10 to $20 \%$. Therefore, it is said in the literatures that material properties is still not yet proven to have an influence on the heat transfer process in the regime of film boiling.

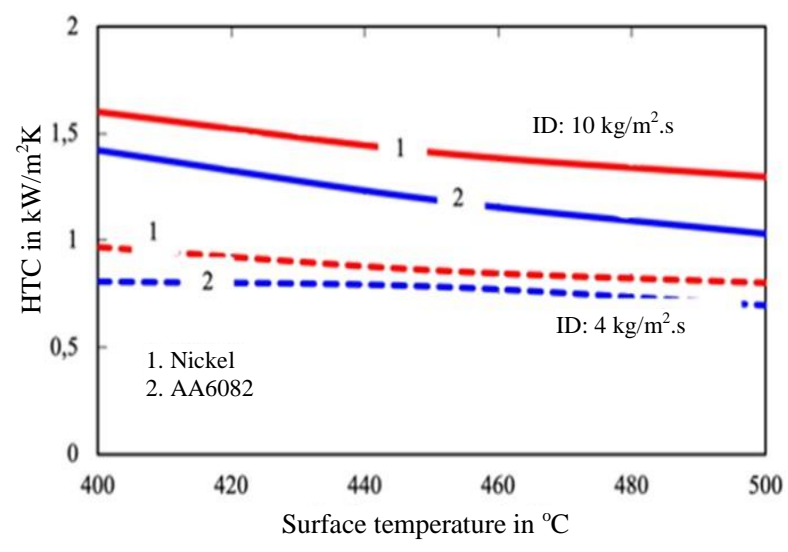

Fig. 8. HTC in the film-boiling regime from the experimental quenching of nickel and AA6082 sample.

\section{Regime of transition boiling}

Figure 9 depicts the trend of Leidenfrost temperature over the spray flux under the use of different material types. A strong influence of material properties to the Leidenfrost temperature is obviously observed by setting a fixed value of spray flux. Mozumder et al. [1] reported that the heat penetration coefficient $\sqrt{\lambda . \rho . c}$ had affected the temperature of Leidenfrost strongly. This coefficient is inversely proportional to the Leidenfrost temperature. It is in line with the result from Ibrahim et al. [30] highlighting that the decrease of $\lambda . \rho . c$ contributes to the increase of temperature of Leidenfrost. Since steel, as reported by Al-Ahmadi et al. [8], has the lowest coefficient, it has the highest Leidenfrost temperature. AA6082 and nickel from own experiment under spray flux of 4.2, 10 and $13.7 \mathrm{~kg} / \mathrm{m}^{2} \mathrm{~s}$, represents the highest and lower coefficient and therefore shows inversely consequence. This proves that material properties significantly influence the start of Leidenfrost transition. The earlier the Leidenfrost transition 
occurs, the shorter regime of film boiling is, and the duration of film boiling determines the duration of whole quenching process. Müller [10] found that under low spray flux, the Leidenfrost Temperatures among different material properties namely Nickel, Brass M37 and Aluminum were not as significant as at the higher spray flux.

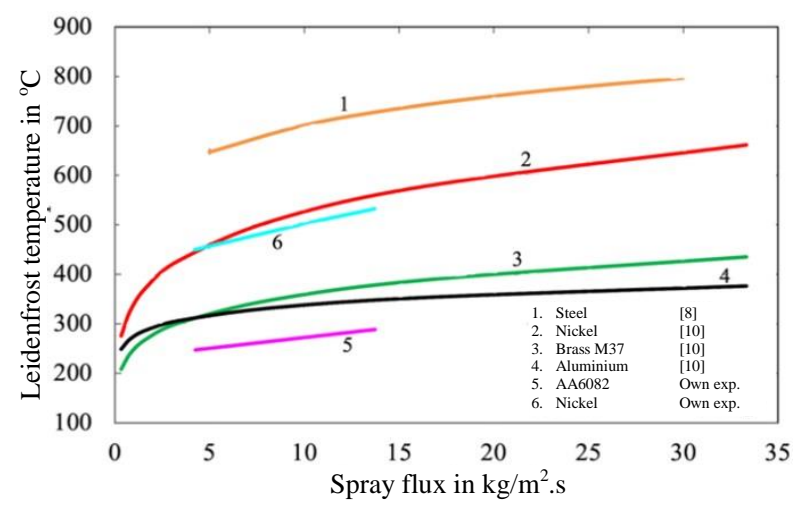

Fig. 9. Leidenfrost temperature trend over spray flux for different kind of metals.

\section{Regime of nucleate boiling}

When the heat flux reaches the maximum value at the corresponding DNB temperature, boiling process phases into the regime of nucleate boiling. This process lasts until water-saturated temperature is reached out. As most of the heat is extracted in this regime, identification on factors influencing the DNB temperature and the maximum heat flux become essential.

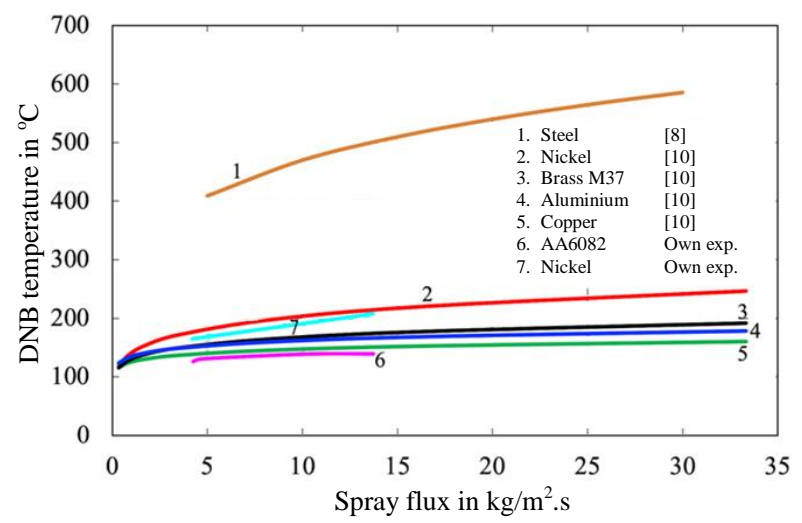

Fig. 10. DNB temperature trend over spray flux under different material types.

Figure 10 depicts the DNB temperature over spray flux under different material types by comparing work from Al-Ahmadi et al. [8] using steel, those from Müller [10] using nickel, aluminum, copper and brass M37 as well as AA6082 and nickel from own experiment under spray flux of $4.2,10$ and $13.7 \mathrm{~kg} / \mathrm{m}^{2} \mathrm{~s}$. Similar to the Leidenfrost temperature, an inverse correlation is also found for the DNB temperature of different material properties. Therefore, steel shows the highest DNB temperature among other materials.

By taking a fixed spray flux point as an example, DNB temperature shows obviously an inverse correlation to the heat penetration coefficient [16]. Besides, it is found that material properties only significantly affect DNB temperatures at the higher spray flux condition.

The maximum heat flux over spray flux for different kinds of metals is depicted in Fig. 11. It shows that maximum heat flux increases with the heat penetration coefficient. It is proven when results from the mentioned works above are compared. An inverse trend is shown up.

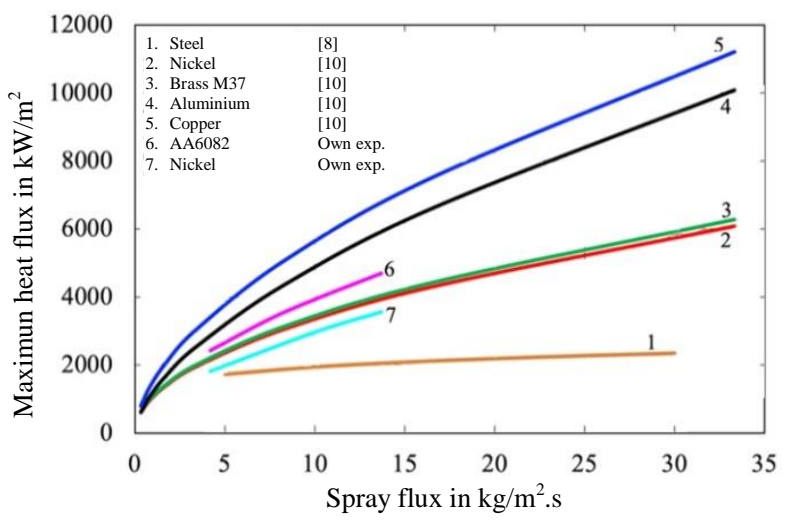

Fig. 11. Maximum heat flux trend over spray flux under different material types.

By considering these two parameters, it is proven that the material properties have a great influence in the regime of nucleate boiling, especially at the higher value of spray flux.

\section{Boiling width characteristics}

Additional information from this work is that the boiling width characteristics were mapped during the quenching process. The total boiling width is defined as the sum of defined regime of transition and nucleate boiling. This information is essential to relate the physical look on the boiling phenomena to the surface temperature and the heat flux. IR images of those two materials at different time and location during quenching process is shown in Fig. 12. Similar technique has been utilized to refer boiling width characteristics due to influence of spray flux, water temperature, initial temperature and salinity. Details can be found in the previous publication [21].

The width of transition-boiling regime is defined as the gap between the Leidenfrost to DNB points. Whilst the gap between DNB to $100{ }^{\circ} \mathrm{C}$ points defines the width of nucleate-boiling regime. Then calculation of the Leidenfrost, maximum heat flux and $100{ }^{\circ} \mathrm{C}$ points propagation is following the previous publication [21]. 


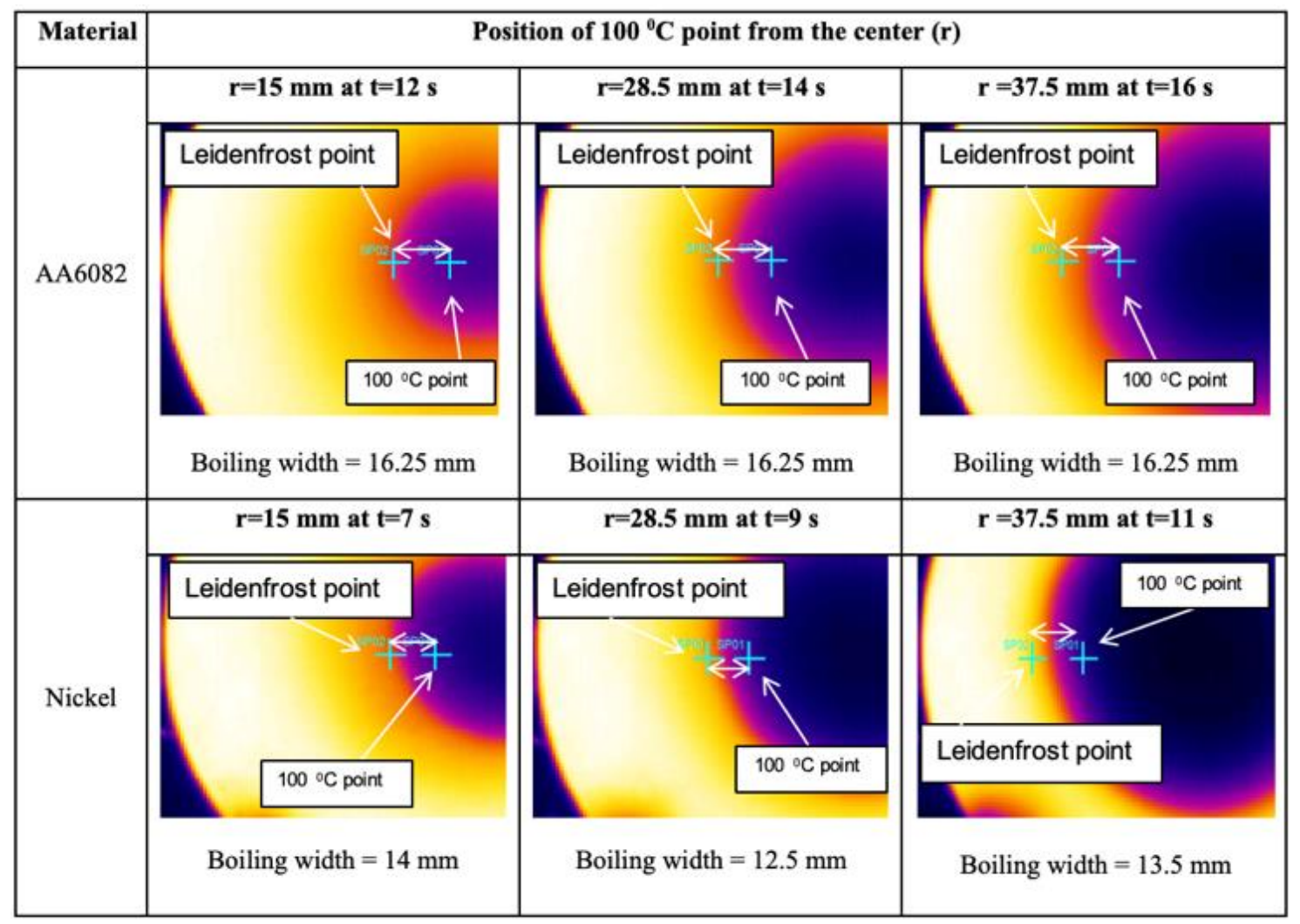

Fig. 12. The width of boiling under different materials with IR mode.

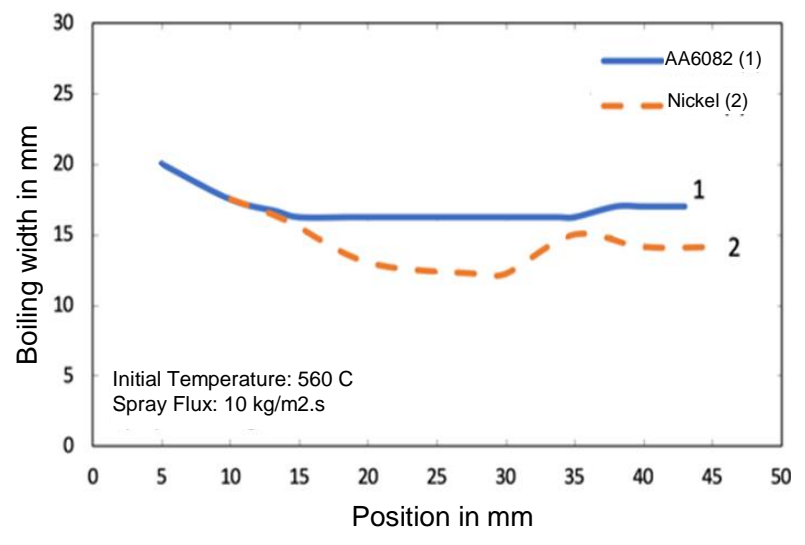

Fig. 13. The width of boiling region of two different materials.

Respectively, review on the boiling width of Aluminum Alloy AA6082 and Nickel sample is depicted in Fig. 13. They were heated up to the same initial temperature of $560{ }^{\circ} \mathrm{C}$ and exposed to the same spray flux of $10 \mathrm{~kg} / \mathrm{m}^{2} \mathrm{~s}$ water. Under this similar condition, the higher heatpenetration-coefficient material of AA6082 would promote wider boiling width than Nickel. It is predicted based on the thermal conductivity $\lambda$ which is dictating the gradient of temperature in the boiling area. By selecting a fixed point, Woodfield et al. [16] reported that with the higher thermal conductivity material, a less steep temperature gradient was measured. It is due to the wider the boiling width formed.

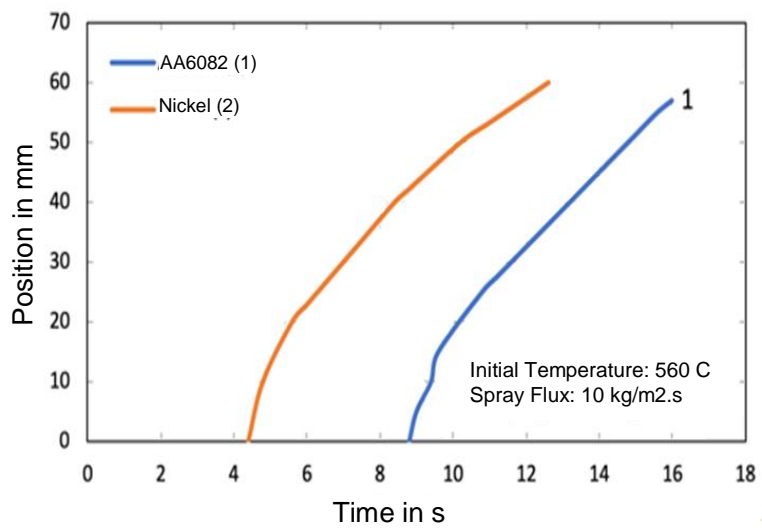

Fig. 14. Comparison of wetting front propagation of two materials.

Figure 14 depicts the propagation of wetting front for AA6082 and Nickel. Lower heatpenetration-coefficient material of Nickel promotes earlier wetting front propagation compared to the higher one (AA6082). Propagation of wetting front marks the Leidenfrost transition. Results from AlAhmadi et al. [8] and those reported by Müller et al. [10] plotted together in Fig. 9 has shown a correlation between Leidenfrost point and heat penetration coefficient of the materials which is in line with this experimental results. Under conditions of high heat flux, Woodfield et al. [16] reported as well that localized surface of lower heat-penetrationcoefficient material of Nickle tends to get cooled easier than AA6082. It is so since Nickel has a thermal conductivity of about half of AA6082. 


\section{CONCLUSION}

In the regime of film boiling, with own developed analytical model of single droplet, the increase of HTC with the decrease of the surface temperature can then be explained. With calculated thickness of favor film, its decrease with the surface temperature become the logical cause to the increase of the heat transfer performance. However, material properties is found to be a weaker function to the heat transfer performance in this regime. In the next regime of transition and nucleate boiling, Leidenfrost and DNB temperatures are found to be inversely proportional to the heat penetration coefficient of the metal while maximum heat flux increases with it. Propagation of Leidenfrost and DNB points over position are the basis for the calculation of boiling width. It was found that due to its higher thermal conductivity AA6082 promotes wider boiling width than Nickel. This has physical meaning that the temperature range where boiling is likely to occupy a larger width on the metal surface results in a lower temperature gradient.

Further research is necessary to apply high speed camera in order to match physical visualization to the analytical result. The existance of vapor film has been believed as the factor impeding the heat transfer during the film boiling. Furthermore, the propagation of wetting front which defines the boiling width has to be physically verified in term of its hydrodynamics, e.g., rebound and splashing during the quenching process.

\section{ACKNOWLEDGMENT}

This project was funded by Hibah Internal Perguruan Tinggi, Universitas Internasional Batam. Technical support from Institute of Fluid Dynamics and Thermodynamics OvGU Magdeburg is highly appreciated.

\section{AUTHOR CONTRIBUTION}

First Author conceived the presented idea based on the result of his experimental works. Second Author encouraged First Author to develop single droplet model in film boiling and then verified the analytical results together. All authors discussed on the results presented in the manuscript. First Author finalized the figures and final manuscript draft.

\section{REFERENCES}

1. A. K. Mozumder, M. Monde and P. L. Woodfield, Int. J. Heat Mass Transf. 48 (2005) 5395.
2. S.-H. Hsu, Y.-H. Ho, M.-X. Ho et al., Int. J. Heat Mass Transf. 86 (2015) 65.

3. G. Liang and I. Mudawar, Int. J. Heat Mass Transf. 115 (2017) 1174.

4. B.-R. Fu, Y.-H. Ho, M.-X. Ho et al., Int. J. Heat Mass Transf. 95 (2016) 206.

5. G. Liang and I. Mudawar, Int. J. Heat Mass Transf. 115 (2017) 1206.

6. M. H. Sadafi, S. González Ruiz, M. R. Vetrano et al., Energy Convers. Manag. 108 (2016) 336.

7. J. Wendelstorf, K. H. Spitzer and R. Wendelstorf, Int. J. Heat Mass Transf. 51 (2008) 4902.

8. H. M. Al-Ahmadi and S. C. Yao, Exp. Heat Transf. 21 (2008) 38.

9. A. Cebo-Rudnicka, Z. Malinowski and A. Buczek, Int. J. Therm. Sci. 110 (2016) 52.

10. H. R. Müller and R. Jeschar, Metallkunde $\mathbf{7 4}$ (1983) 257.

11. Sabariman, Y. Fang and E. Specht, Heat Transf. Eng. 40 (2019) 16.

12. A. R. Pati, A. Tayal and S. S. Mohapatra, Chem. Eng. Sci. 218 (2020) 1.

13. Sabariman, Heat transfer analysis in metal quenching with sprays and jets, 1 st ed. Barleben: Docupoint Verlag, 2015.

14. A. Cebo-Rudnicka and Z. Malinowski, Int. J. Therm. Sci. 145 (2019) 1.

15. A. Labergue, M. Gradeck and F. Lemoine, Int. J. Heat Mass Transf. 81 (2015) 889.

16. P. L. Woodfield, A. K. Mozumder and M. Monde, Int. J. Heat Mass Transf. 52 (2009) 460.

17. K. Takrouri, J. Luxat and M. Hamed, Nucl. Eng. Des. 311 (2017) 184.

18. A. A. Tseng, M. Raudensky and T. W. Lee, Heat Transf. Eng. 37 (2016) 1401.

19. N. H. Bhatt, D. Chouhan, A. R. Pati et al., Exp. Heat Transf. 30 (2017) 369.

20. R. Guo, J. Wu, H. Fan et al., Appl. Therm. Eng. 107 (2016) 1065.

21. Sabariman and E. Specht, Exp. Heat Transf., 31 (2018) 391.

22. G. Liang and I. Mudawar, Int. J. Heat Mass Transf. 106 (2017) 103.

23. R. Dou, Z. Wen and G. Zhou, Int. J. Heat Mass Transf. 90 (2015) 376.

24. N. H. Bhatt, A. R. Pati, A. Kumar et al., Appl. Therm. Eng. 120 (2017) 537. 
25. R. Guo, J. Wu, W. Liu et al., Exp. Therm. Fluid Sci. 72 (2016) 249.

26. B. Hadała, Z. Malinowski, T. Telejko et al., Int. J. Therm. Sci. 136 (2019) 200.

27. E. Specht, Heat and Mass Transfer in Thermoprocessing, 1st ed. Essen: VulkanVerlag GmbH, 2017.
28. V. G. Labeish, Exp. Therm. Fluid Sci. 8 (1994) 181.

29. J. Breitenbach, I. V. Roisman and C. Tropea, Int. J. Heat Mass Transf. 110 (2017) 34.

30. S. A. Ebrahim, S. Chang, F.-B. Cheung et al., Appl. Therm. Eng. 140 (2018) 139. 